\title{
Commission incomplete: exploring the new model for purchasing public services from the third sector
}

\author{
JAMES REES*, ROBIN MILLER ${ }^{* *}$ AND HEATHER BUCKINGHAM ${ }^{* * *}$ \\ *The Open University Business School, Open University, Milton Keynes, MK7 6AA, United \\ Kingdom \\ email: james.rees@open.ac.uk \\ ** Health Services Management Centre, Park House, University of Birmingham, Edgbaston, \\ Birmingham B15 2TT, United Kingdom \\ email: r.s.miller@bham.ac.uk \\ *** Department of Theology and Religion, University of Birmingham, Edgbaston, Birmingham \\ B15 2TT, United Kingdom \\ email: h.buckingham@bham.ac.uk
}

\begin{abstract}
The concept of commissioning has risen in prominence in recent years as a result of ongoing reforms to the funding and delivery of public services in the UK. The model of commissioning constructed by policy has however been overlaid on existing practices, which themselves differ between different service areas. This paper, focusing on commissioning of third sector organisations (TSOs) in the field of community mental health services, shows that its introduction has not led to the straightforward public sector 'marketisation' that advocates desire or that critics fear. Instead, commissioning has led to an indeterminate outcome or 'halfway house' position in which the status and role of commissioning remains somewhat muddled - both internally to participants within public sector organisations and externally in terms of the experience of the interface by TSOs. We found that commissioning as it is actually practiced remains contested and political - it is a highly relational process dependent on personal practices and skills and on personal relationships between stakeholders - and is therefore not fully managerialised or marketised. This has implications for the policy and practice of commissioning and the interpretation of more 'open' public services.
\end{abstract}

\section{Introduction}

The concept of commissioning has come to occupy a central position in debates over the reform and management of public services in England after years of policy whose underpinning rationale was to move various services outside of the public sector and to recast public sector agencies in a 'system leader' role as strategic overseers of a more mixed economy of welfare (Murray, 2011; Glasby, 2012). This looks certain to continue under the majority Conservative government elected in May 2015, building on the Health and Social Care Act 
2012. An approach based on commissioning is the culmination of longstanding reforms beginning in the new public management era with the introduction of outsourcing, compulsory competitive tendering, the purchaser-provider split in health and, later, a variety of efforts in the New Labour period aimed at improving procurement practice across the public sector (Bovaird et al., 2012; Lonsdale, 2012). In terms of the framing of policy, commissioning is posed as distinct from, indeed superior to, procurement because it ought to involve a 'whole system' approach, inevitably portrayed as a cycle involving recursive steps of consultation, design and purchase, and re-design (Cabinet Office, 2006). Commissioning has had a particular resonance for the third sector: cast in the New Labour 'partnership' discourse as specialist providers with unique attributes, they were also thought to have been disadvantaged by previous 'narrow' competitive tendering approaches (Carmel and Harlock, 2008). Some commentators thus viewed commissioning as potentially a positive development for state-sector relations (Navca, 2010).

However, commissioning has been a contested concept, with debates hinging on the extent to which successive governments - from New Labour to the Conservative Government formed in $\mathbf{2 0 1 5}$ - have, despite some 'progressive' rhetoric, viewed commissioning simply as a tool within the agenda to 'open up' and privatise the delivery of public services (HM Government, 2011). Under Conservative-led administrations, these trends have accelerated, with commissioning viewed in a more narrowly instrumental manner as a marketbased mechanism to drive through greater externalisation, introduce greater competition, reduce costs, and arguably to favour commercial providers. This is set against the backdrop of wide-ranging structural changes to the NHS in the 2012 Health and Social Care Act, as well as new commissioning arrangements for probation services and other fields (Dominey, 2012; Milbourne and Cushman, 2015). At the same time, commissioning implies a complex set of shifts in governance arrangements, including the need to strategically manage a 'market' of providers, and to focus on achieving particular outcomes for targeted populations (Rees, 2014). Commissioners are meant to use their purchasing and influencing power to ensure that publicly funded services are shaped to achieve the desired outcomes with the resources available (Miller and Rees, 2014). Moreover the fact remains that there is continuity between both New Labour's 'partnership' and the Coalition's 'Big Society' rhetorical emphasis on the role of the third sector (compare Cabinet Office, 2006; HM Government, 2011). The role, trajectory and experience of third sector organisations in engaging in commissioning and public service markets thus remains an important object of study.

This paper reports on a study with exactly this focus, in the field of local mental health services, which are commissioned by local authorities and the NHS in the case study conurbation. There are three main reasons why this 
focus is important in a wider social policy context. Firstly the third sector is a significant provider of services within the landscape of mental health provision, where it is both contracted to provide publicly-funded services as well as a range of services from charitable and voluntary resources which can be considered part of the mix of services provided to the public. Secondly, as mentioned, successive governments have placed considerable emphasis on encouraging greater involvement of the third sector in mental health service provision. Studies have consistently drawn attention to the difficulties and tensions experienced by TSOs when engaging with public sector commissioning processes. They have allegedly struggled to win contracts, baulked at threats to their independence and autonomy from intrusive monitoring requirements, and some have argued they have been progressively squeezed out of public services markets (Neville, 2010; Damm, 2014). Thirdly, therefore, it is important to reflect on whether commissioning is working well in terms of engaging a wide variety of providers, and is providing a platform that is fair (a 'level playing field') and in what ways it might be improved for the good of service users and citizens more generally. 'Fairness' has particular relevance when judging whether the outcome of commissioning - diversity of supply versus domination ('privatisation') by private sector providers - ultimately lends credence to commissioning as an approach. Additionally, an important advantage of this study is that the interview respondents from local TSOs have often been working in the area for a long period, presenting the opportunity for a quasi-longitudinal view on 'pre- and post-commissioning life'.

The research underpinning this paper had two broad aims: to explore the extent to which commissioning policy had been implemented in the field of mental health services and to understand TSOs' experiences of the commissioning environment. Advocates of the commissioning, choice and competition agenda have argued that commissioning will lead to more diversified and effective services, provided outside of the public sector at lower cost (Blatchford and Gash, 2012). Academic perspectives tend to be more critical, suggesting that commissioning is central to an agenda of marketisation and privatisation, weakening democratic control of services (Larner and Butler, 2005; Davies, 2008). However, between these poles there is a relative lack of literature based on empirical research examining in detail the reality and impact of commissioning in practice (Huxley et al., 2010; Martikke and Moxham, 2010; Bovaird et al., 2012). Research has however highlighted that the status and ultimate impact of commissioning in affecting the design and delivery of health and social care systems has been ambiguous, and commissioning has not always been well understood by different groups of professionals (Checkland et al., 2012; Harlock, 2014). The research reported here suggests that the status of commissioning is more ambiguous and contested than either side has acknowledged, and there is significant continuity with past approaches. Commissioning is not necessarily the 
transformative mechanism that either side hopes or fears. The paper first sets out the policy and research literatures that underpin moves to commissioning, before outlining the approach to the research. Next it outlines the findings in two main areas: the degree to which there has been change associated with the introduction of the commissioning approach, and whether the commissioning 'cycle' has been implemented; and the emerging consequences for relationships within the provider 'market' in mental health services. The final section summarises conclusions and implications.

\section{Commissioning and Local Mental Health Services}

Commissioning is invariably envisioned as a cyclical process, and has been defined as the 'cycle of assessing the needs of people in an area, designing and then securing an appropriate service' (Cabinet Office, 2006: 4; Glasby, 2012). Although divergent approaches have operated concurrently across policy domains and at different scales of government (Bovaird et al., 2012), there are core elements within them gathering data on a population or sub-populations in order to understand current and future need, working with other partners in order to prioritise areas for investment/disinvestment, and public bodies deploying their power as purchasers within mixed economies of provision to promote choice and efficiency (Murray, 2011). Procurement is often portrayed as a sub-set of commissioning activity, either a discrete step in the commissioning cycle, or a separate but linked cycle that runs within the direction set by the commissioning strategy. Government guidance also underlines the importance of the active engagement of people who may access these services, as well as local communities and agencies with specialist and/or local knowledge in the whole process - and thus the role of third sector organisations (TSOs) as contributors and intermediaries has often been stressed in addition to their delivery role (Navca, 2010). A key objective of the current mental health strategy is to enable recovery through supporting people to have more control over personal decisions and symptoms, and to have lives 'beyond illness' (DoH, 2011; Slade, 2009). Commissioners can promote a recovery model by engaging people with mental health problems in commissioning processes, and also through opening up the opportunity for personal budgets (Heginbotham and Newbigging, 2013).

In relation to the third sector, a consistent theme has been disappointment with progress in fully involving TSOs throughout the commissioning cycle; and thus failure to maximise the role of the third sector in contributing novel approaches and user and community 'voices' (Murray, 2011; White, 2011). Literature highlights that TSOs face obstacles to greater involvement in commissioning, including knowledge gaps on both sides, as well as TSOs' lack of the financial capacity, skills and size to engage in such timeand resource-consuming activities (Packwood, 2007; Martikke and Moxham, 
2010). It has also highlighted fears of the adverse impact on the sector through threats to its independence, mission and long-term sustainability, suggesting that even potentially 'contracting-ready' TSOs might shy away from commissioning processes (Osborne and McLaughlin, 2002; Buckingham, 2009). The combination of these issues influenced a policy debate that sought ways in which to improve commissioning, as demonstrated in the idea of 'intelligent commissioning' (Navca, 2010). Furthermore, it was recognised that in the context of local public sector commissioning, the existing 'ecosystems' of third sector providers may be particularly fragile. An acceptance of this weakness was embedded in the Labour government's 'partnership' approach to building up the third sector role in public service delivery: significant resources were devoted to building capacity and professionalisation through programmes like Futurebuilders, as well as the creation of a Compact to encourage high standards in financial relationships prior to 2010 (Carmel and Harlock, 2008; Macmillan, 2010). On the public sector side, an initial National Procurement Strategy was followed by a National Programme for Third Sector Commissioning aimed at improving the understanding of the third sector by commissioners through training and information sharing; as well as eight principles of good commissioning (ODPM/LGA, 2003; Murray, 2011). To summarise therefore, substantial expectations have been loaded onto the concept of commissioning: underpinned by an assumption that, at least when properly conducted, commissioning should be cyclical, inclusive and lead to an improvement in services.

The mental health policy context in England is one in which there have been major improvements over recent years in relation to the closure of longstay hospitals and the provision of community-based crisis services. People with mental health problems continue though to be subject to considerable social disadvantage in relation to employment, general health and offending rates (King's Fund, 2012). The current strategy in England emphasises the need for engagement of services beyond specialist mental health provision if people's wellbeing is to be improved, although concerns continue regarding the level of funding provided for specialist services ( $\mathrm{DoH}, 2011$; $\mathrm{CEP}, 2012)$. The potential benefit of involving the third sector in both the commissioning process and in service delivery has been underlined in mental health policy and guidance. Whilst approximately a quarter (26 per cent) of the services purchased by the NHS in 2011/12 were provided by non-statutory (i.e. private and third sector) organisations (Mental Health Strategies, 2012), NHS providers continue to dominate key service areas such as crisis support, clinical care and community teams. Common services provided by the third sector are advice, counselling and education, with the sector also being dominant or strong players in advocacy, employment, respite and home support services. Beyond their role in direct delivery, TSOs have historically played a significant role in raising awareness of 
TABLE 1. Case study characteristics

\begin{tabular}{|c|c|c|c|c|}
\hline $\begin{array}{l}\text { Local authority } \\
\text { location }\end{array}$ & $\begin{array}{l}\text { Population size } \\
\text { (approx.) }\end{array}$ & Type & $\begin{array}{l}\text { Number of interviews } \\
\text { (TSOs/ commissioners) }\end{array}$ & $\begin{array}{l}\text { Gender of } \\
\text { respondents } \\
(\mathrm{M} / \mathrm{F})\end{array}$ \\
\hline 1 & $1.1 \mathrm{~m}$ & Central urban & $(14 / 3)$ & $(10 / 7)$ \\
\hline 2 & 315,000 & Urban/suburban & $(4 / 1)$ & $(1 / 4)$ \\
\hline 3 & 205,000 & Suburban/rural & $(5 / 2)$ & $(2 / 5)$ \\
\hline
\end{tabular}

the needs of people with mental health problems, in developing and sharing new approaches, and in campaigning for changes in law and policy (Miller and Rees, 2014). These roles continue with, for example, significant involvement in the development of the implementation framework for the current national strategy (DoH, 2012).

\section{Methodology}

The research followed a sequential mixed methods design (Creswell and Clark, 2011) involving three main stages. The first included a review of academic and policy literature, summaries of which were published in Miller (2013) and Rees (2014); as well as consideration of relevant policy and practice grey literature. A large English conurbation comprising three contiguous local authorities (LAs) with contrasting spatial and demographic characteristics, in a broadly EastWest orientation across the metropolitan area was selected as a case study (see Table 1 for brief characteristics). A small number of informal interviews were carried out with respondents from sector representative bodies and larger TSOs providing mental health services in the area. These scoping interviews were used to further explore the issues identified through desk-based research and to identify which public sector commissioning agencies were involved (principally local authority departments and the NHS). The second stage involved an online survey of mental health TSOs in the three LAs, which explored: TSOs' experience of being 'procured' by the public sector, their experience of the commissioning cycle, and the impact of these processes on their organisation. Potential respondents were identified through lists of mental health TSOs held by local infrastructure bodies, supplemented with web searches. The means of contacting them varied depending on the completeness of local 'listings', and included direct email approaches and advertisement on the infrastructure body's websites. Consequently the questionnaire was well targeted but there was no way to establish the response rate. The survey elicited sixteen valid responses, with a roughly equal split between the three local authorities. The data were collated and analysed qualitatively due to the small sample size. Despite the infeasibility of quantitative analysis, the survey was successful in eliciting TSOs' experiences 
of - and attitudes to - commissioning, confirming the agencies involved in commissioning, and refining the sample of TSOs for follow up through in-depth interviews.

The third stage involved in-depth qualitative interviews carried out with representatives of TSOs $(n=23)$ and individual commissioners $(n=6)$ (see Table 1). A purposive sample of TSOs was constructed with the aim that it should reflect the range of services provided by TSOs for people with mental health difficulties. These services were: advocacy and representation; social care (including domiciliary care, residential care and day activities); supported housing; employment; advice and counselling; and support for carers. The purposive sample was built from organisations identified in scoping activities, and from the survey responses, and was further expanded through 'snowballing' from interview respondents, as well as attendance at local 'network' events such as 'Third Sector Forums'. In the instances where interview respondents had responded to the survey, their answers to the questionnaire were probed in more depth and, once this was exhausted, a semi-structured interview schedule was used. The schedule explored three main themes: perceptions of the difference that commissioning policy had made, and whether the commissioning cycle operated in practice; the impact of commissioning on organisations and their relationships with commissioners and other TSOs; and the degree to which services were becoming better integrated.

The majority of TSO interviews were carried out with either chief executives or senior managers. But in some cases, they were joint interviews involving a senior manager and a more 'frontline' employee (for example, a chief executive and a project worker). Commissioners were identified through the TSO interviews, as well as the earlier scoping activities detailed above. Relevant commissioners worked in local authorities or Clinical Commissioning Groups, or in joint NHS/LA commissioning bodies. Interviews were conducted in a similar manner, and in the same period, using a revised semi-structured interview schedule. As a result of the relatively small number of organisations, and tightlydefined geographical area, in this paper interview quotations are fully anonymised and attributed only to 'TSO' or 'commissioner'. The survey data are not explicitly reported on or quoted in this paper. All interviews were recorded and transcribed and the data analysed through a framework method (Gale et al., 2013). The transcripts were read by all the authors in order to identify a 'longlist' of themes that broadly reflected the research questions and interview schedules, while allowing for the possibility that further themes would emerge from the data during coding. The researchers met to share these themes and further refine the codes which were then applied to the data. After coding, key data were entered into a spreadsheet matrix organised by theme, to permit further systematic analysis of groupings within the interview data. Finally, the themes were refined through 
further discussion within the research team and re-examination of the original data, and used as the basis for the analysis reported in the following sections.

\section{Findings}

\section{A. Life before and after the advent of commissioning}

As noted above, the interviews took advantage of the fact that respondents could reflect in a quasi-longitudinal sense on their and their organisations' experience of the environment over the period in which commissioning policy had been introduced. In essence, respondents were encouraged to reflect on what life was like 'before commissioning', how things had changed subsequently (if at all) and, more contemporaneously, the extent to which commissioning operated in the cyclical manner envisaged in policy models. There was agreement between TSOs and commissioners that the situation that existed in the period prior to commissioning - a period marked by greater informality, widespread use of grants, and less pronounced contestation of services - was far from ideal. There was consensus between the groups that the public sector had not always been sufficiently diligent in using funds, including services being continued that were potentially not the most effective approach, or where there was insufficient challenge to providers who may not have been best placed to deliver a service:

We were in danger of some services just being re-commissioned and re-commissioned and recommissioned without much thought going into 'are these clients actually achieving long-term outcomes from using this service?' (TSO)

Some of the historic contracts that I've seen were bloody stupid at the outset; what on Earth possessed us to suggest it and what on Earth possessed the commissioners to buy it, in terms of the nature of the service and the cost of it? (TSO).

Commissioners acknowledged many of the criticisms of the historical situation that were made by TSOs. Perhaps unsurprisingly though, being more familiar with the strategic intention of their organisation, the TSOs argued that commissioning - and in particular, the implementation of a more coherent cycle - had had a real impact on the core relationship between commissioners and providers, as well as on resultant service quality. As a result, it was argued, the public sector now had a better awareness of what money was being spent and were in a better position to scrutinise and review how it was being used in prospect:

I think we're getting more sophisticated . . . because the information's getting better. In the past you know trying to get any mental health information was just an absolute nightmare. You know, you couldn't rely on it, it was never reconciled, it was never validated, you know a lot of it was paper records, a lot of it wasn't put on in a timely way. It was really difficult to have reliable information that you could - you could base your work on ... (Commissioner).

A second area of consensus concerned a strong sense of underlying continuity - particularly in the core financial relationship between individual TSOs and 


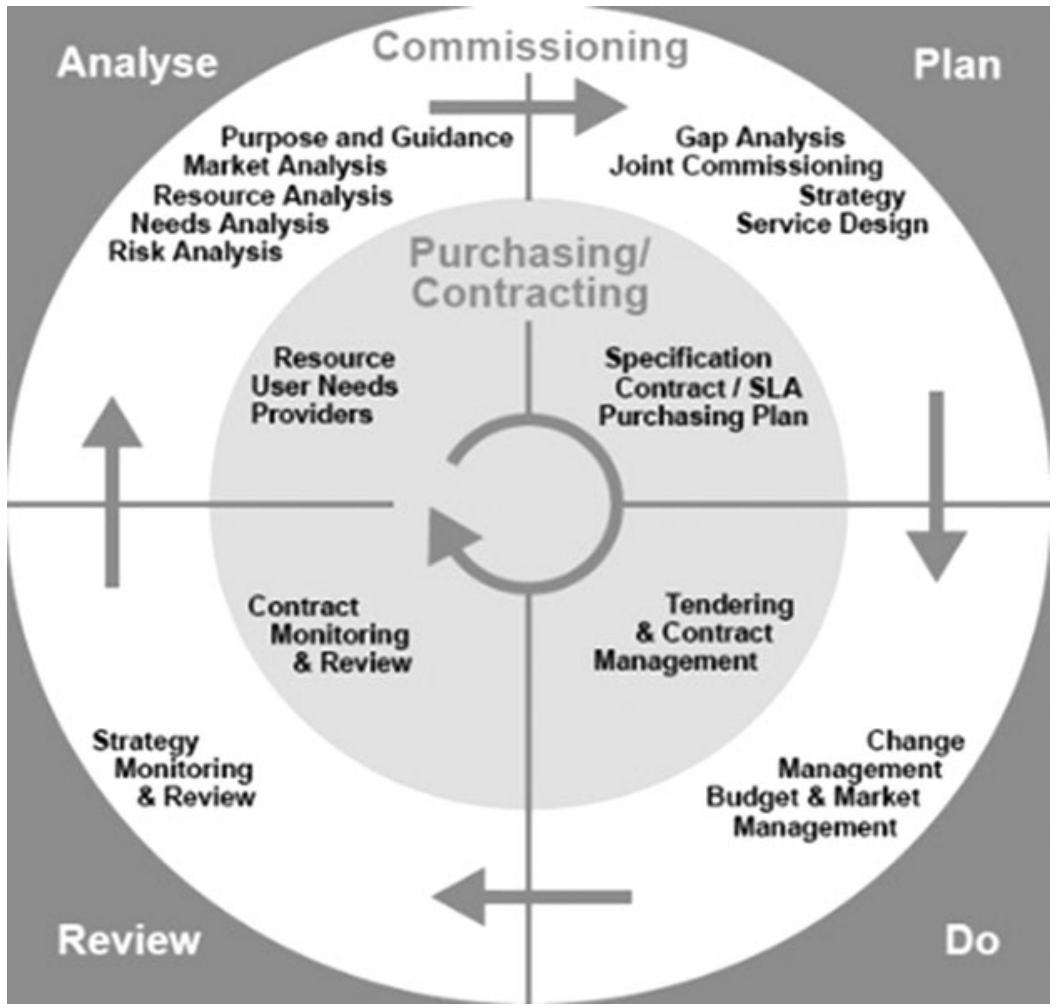

Figure 1. The commissioning cycle. Source: Institute of Public Care (IPC, 2008)

their commissioning agency. For many of the TSOs in the study, contracts had been 'rolled over' for many years, without being subject to an overt competitive tendering process. As a result, the idea of distinct 'before' and 'after' commissioning periods - despite acknowledgement that a policy shift had occurred - resonated with few respondents:

The issue is quite complicated isn't it, in terms of when the commissioning actually replaced what was there before, because there's all the overlap in terms of contracts and... [there is doubt, therefore] I think, whether commissioning actually is that different. (TSO)

When it comes to a more contemporary experience of commissioning processes, and particularly the extent to which a commissioning cycle has actually been implemented, views were very mixed. In variance to the idealised model (Figure 1) TSOs reported experiencing commissioning in a truncated form. For them the key periods were a) a phase spanning the competitive tendering process, incorporating: 'pre-tendering' (consultation, dialogue with commissioners) and 'tendering' (competitive phase); b) a phase of 'contracting, delivery and 
monitoring'. Most TSOs described commissioning as something that was being done to them: 'being commissioned' which in many ways was just a different way of saying 'being purchased'. There was little sense that TSOs felt consistently engaged in public sector 'review, analysis, plan' activities, but rather, on an ad hoc or informal basis. In contrast, some TSOs, engaged in specific sub-fields which had undergone a period of policy redesign or restructuring, reported being involved in a much more thorough engagement with commissioners. This was cited as evidence that commissioning policy had indeed had an impact on practice.

Furthermore, TSOs were often highly critical of those steps within the commissioning process that could be identified. To take 'competitive tendering' first, TSOs complained of inconsistent approaches between different public sector agencies and most reported experiencing frustration caused by delays, apparent u-turns and occasionally unexplained termination of tender processes. Concerns were also expressed about the way in which tenders were advertised, with particular reference to the difficulty for smaller organisations in keeping abreast of opportunities, and the negative impact that uncertainty over funding had on the provision of existing services:

It's always been like that since I've known it, it's very chaotic communication. And sort of sudden attempts to consult the third sector and then they never really come to anything... I think with all these things they have tried to have a cycle but there's been slippage. (TSO)

In relation to the next phase, 'contracting and delivery', TSOs commonly reported that receiving a contract did not spell the end of financial uncertainty and instability but, rather, continuing frustration or 'chaos'. Indeed, for a number of TSOs, simply getting a copy of their contract appeared to be a challenge in itself:

It's still sometimes all too difficult to finish off with a commissioner the niceties of contractual agreements and other things and so it can be hard work getting proper documentation about contracts that you're commissioned to provide. (TSO)

Some saw willingness to engage with commissioning as a means to gain greater assurance about what funding would be provided to them. For some, the process was compared favourably to scenarios they had experienced in the past in which grants were renewed on a short-term basis whilst longer-term funding decisions were made, and they were 'kept in limbo'. However, this has to be set against a more widespread perception that the process was complex and confusing, making forward financial planning and management difficult:

I've currently got about four different extensions on the go from the local authority, because they are just slowly getting their acts together, aren't they? The situation we're in at the moment is that we are uncertain beyond September whether we've got any NHS work under contract. (TSO) 
Finally, TSOs were also critical of the way monitoring was carried out by commissioners. Monitoring was described as often being based on quantitative measurements of service uptake rather than capturing the experience of people who were supported. This was seen to reflect a 'hands off approach by commissioners in relation to the contracted services and several participants expressed a wish for a more robust, active and engaged monitoring process:

They're very used to quantitative targets ... and giving you numbers and number-crunching and all this sort of thing, but they don't pay attention to the soft outcomes and they don't pay attention to the amount of time that it takes for people like support workers, for example, to have to deal with a case, and every case is different. (TSO)

Commissioners, while acknowledging such concerns, as well as constraints related to capacity and expertise, also levelled criticism at TSOs. They reported differing experiences of the willingness of TSOs to engage with such processes, with examples of TSOs resisting attempts for more robust frameworks:

There's a combination in terms of commissioning you've got to really have that sort of level of discipline to have both sides in it. You can't just give me a verbal update; we've got to have that evidence of what they've done and all the rest of it. (Commissioner)

As the findings outlined here illustrate, the issue of change over time is far from straightforward and perceptions of the issue, by respondents from TSOs in particular, are variable, depending on their individual and organisational experiences and characteristics, and their position in the market. On the one hand, many respondents struggled to define a clear periodisation of before- and after-commissioning: a significant factor here was a clear sense of continuity stemming from the long-term nature of contractual relationships. On the other hand, respondents - from TSOs and commissioning agencies alike believed that commissioning policy had ushered in more rigorous approaches to accountability, assessment of spending and service monitoring; they also recognised an increase in contestability and the opportunities and challenges that resulted. For yet others, the sense of continuity was reinforced by an awareness that the core communicative and financial relationship between public sector and providers had historically been, and continued to be, a source of frustration and uncertainty. This relational aspect - between commissioners and commissioned, and between providers competing in a 'market' - is therefore crucial, and is explored in more depth in the next section.

\section{B. Commissioning in a relational perspective: competition and market stewardship \\ Managing a (fragile) provider market}

Commissioners are required to play a difficult balancing act in that, to be regarded as successful, commissioning processes need to demonstrate 
that they can adequately steward a local 'market' of providers, which can include public sector agencies, to create services that meet expectations (HM Government, 2011). Commissioners have a difficult task in balancing this role with sometimes competing requirements to ensure a relatively transparent and fair competitive process that is regarded by providers as above board (for instance, one local authority in the study had experienced a legal challenge to at least one procurement process). The 'relational' side of their role - consultation, and attendance at provider forums etc - inevitably requires the development and maintenance of inter-personal relationships. Clearly, however, this is a highly 'positional' matter, with TSOs perceiving the competitive environment in different ways depending on their position in the market and, once again, views often varied concerning appropriate levels of both formal competition and the 'cosiness' of longstanding relationships.

Commissioners stressed that professionalism and probity were key aspects of their role, particularly in relation to setting parameters that create a competitive and open process for the allocation of funding. Although there is no legal or policy requirement that commissioners will deploy competitive approaches in the awarding of all grants and contracts, there is an expectation that they will consider all the potential procurement options and be able to justify why a grant or contract was rolled over or newly allocated to a single organisation rather than being put out to tender. Commissioners suggested that they tried to deploy the mechanism that they saw as most appropriate for the service in question, including working developmentally with an organisation if needed:

We... went formally through the single provider route to procurement because actually what we wanted to do was ensure that we've got the same providers so that actually the capacity across the localities could be flexed according to where the needs were presenting. (Commissioner)

There was widespread support from TSOs for the opening up of funding opportunities to other organisations rather than an existing recipient being supported ad infinitum, and thus potentially opening the door to new ways of working. This was viewed as having benefits in terms of a better use of public sector funding. But equally for TSOs themselves it was seen as a positive move in that it potentially expanded opportunities to provide new services, increase the range of services, or move into new geographical areas:

It probably has opened up more things for us ... so I think when you had a sort of grant-based regime of doing things, I think it limited the third sector to doing a quite narrow niche of activities which were, on the whole, to the periphery of things. (TSO)

That is not to say that TSOs did not harbour fears about the impact of more competitive approaches to the allocation of funding. This was particularly the case for smaller organisations, who were concerned that they would not have the 
infrastructure, capacity or business skills to compete against larger third sector, private or NHS organisations:

We're very good at the grassroots level work and require us to get some good results, but we're not good at doing the business end and building the key relationships, marketing what we do, selling what we do. We don't have the resources. We've never built that kind of skill-set within particularly small organisations. (TSO)

Competition had also opened up the local market to a greater variety of providers, with some - particularly housing-related - TSOs describing their main rivals as increasingly being from the private rather than third sector. Whilst commissioners did value the characteristics seen to be connected with the third sector their primary interest was in purchasing from an organisation that could deliver effectively:

As long as someone provides the right service for the right person at the right price it's not for us to judge as to whether they happen to be registered with the Charity Commission or floating on the stock exchange, it's our job to concentrate on the person who's receiving the service. (Commissioner)

As highlighted in the previous section, views on competition varied considerably amongst TSOs, reflecting a range of factors such as the size and capacity of organisations, their experience and time within a marketplace and, more intangibly, their culture and mission. Each influenced their sense of the 'room' within the market and the 'threat' posed by other providers and funding shifts (Macmillan et al., 2013). Some TSOs were confident in both competing for business and also in undertaking relationship building with commissioners as a way of 'soft selling' to them. The latter approach had led to some TSOs being allocated new funding without going through competitive processes. Strategies deployed by TSOs to win additional funding without a tendering process included piloting a service through their own resources and then using the evidence of its impact to convince a commissioner of its worth. It is worth noting, however, that the competitive environment is multi-dimensional and asymmetric: TSOs reported competitive tensions with public sector agencies, in particular with the local NHS Foundation Trust.

\section{Process or people? The realities of commissioning practices}

Despite the move to more formality in funding processes, most TSO respondents emphasised the importance of the quality of the relationship with key individuals within commissioning organisations. A strong and enduring relationship was seen as important for fostering trust between commissioner and provider, and it was also seen as a pre-condition for the (often-desired) flexibility from both parties in what was delivered within a contract, and more informal sharing of ideas for service improvement. An established relationship meant that 
commissioning decisions to put out a current service to tender could be more easily accepted and managed:

Our relationship with the Commissioners has been sufficiently strong for us to say pretty much what we want to say. She's lovely, lovely, and I mean, she's as straight as a die ... she said to me basically, you know, in 2014 we're going to have to be looking at all advocacy services with a view to tender. Well, okay, fine. (TSO)

Equally, many acknowledged that such personal relationships might be seen as having a 'dark side' involving a risk of complacency and the perception of a 'closed shop' of providers. For others, however, a close working relationship between commissioner and provider was justified where (TSOs in particular) brought expertise to the table that commissioners were lacking:

On occasion it has been as blunt as [commissioners asking]: 'Well how do we get out of this mess?' So we are proud of the relationship that we've nurtured locally but if we can't nurture a good relationship like that then there's something wrong with us; we're local, we're communitybased, we're third sector... our interest is [this local authority area] and we've been here a bloody long time. (TSO)

Inevitably, with the efficacy of commissioning so dependent on the 'relational' personal qualities and soft skills commissioners must possess, there is a question mark over the extent to which they have been equipped with the complex skills required. Recent government policy that has encouraged a focus on improving the skills of commissioners and enhancing the professional standing of the role appears justified given the emphasis placed on this issue by TSOs (University of Birmingham, 2014). Commissioners for their part stressed the complexity involved in procurement and contracting, with some being candid about their own confidence and the capacity of their organisations to respond sufficiently to these demands:

Contracting is a very, very specialist skill. You know I as a commissioner have not got the contracting nous or the legal knowledge... You know, that's one of the big difficulties. You need proper contracting capacity to be able to deliver those. (Commissioner)

More generally, the interview data make clear the vulnerability of the public sector commissioning function to the loss of key staff within the commissioning team, whether through redundancy, promotion or relocation, or new demands on their time. An important part of the backdrop to such concerns were the expected impacts of reforms associated with the Health and Social Care Act 2012, as well as austerity-related cuts, which were just beginning to be felt in the research period:

I think the changes in the infrastructure and the management... impacts on the consistency of where we go. We get so far and I think it kind of halts because suddenly the commissioners change or there's a reshaping of the structures and we kind of stand still for a while and then we go back a bit and then we go forward a bit. (TSO) 
It was also widely perceived that little was being done to offset such problems through, for example, more robust approaches to information-sharing and contractual systems within the public sector. TSOs reported that they had repeatedly re-provided basic information on their organisations and what they had been commissioned to deliver, and had to re-educate commissioners on the underlying thinking behind local strategies. Finally, co-ordination between the work of different service areas of the public sector has been recognised as a vital issue in general and within mental health in particular (Dickinson et al., 2014). Co-ordination appears to have been problematic on a number of levels: Commissioners were themselves working in agency or user-group silos both between and within the same organisations; they did not always seem to be able to influence the practice of their professional colleagues within social work and NHS mental health teams to co-operate with each other or the voluntary sector; and as a consequence users often experienced services as fragmented and confusing.

I'm not sure, having been commissioned originally through the PCT, that it was ever joined up in the first place. I think there was NHS within NHS within NHS still. There's four levels of NHS that aren't talking to each other already potentially. (TSO)

The structural separation of commissioners and commissioning teams was thought to be mirrored in, and to some degree generated by, the organisation of budgets, with TSOs perceiving that commissioners were in competition to attract or maintain the budget available to their user group. This led to a number of examples in which commissioners appeared to be in dispute about who should pay for a contracted service, which resulted in TSOs being passed between organisations or teams.

\section{Discussion and Conclusion}

This research examined a case study of local commissioning - within a defined geographical and service field - and with particular focus on TSOs, who are significant providers of local mental health services. Those in favour of marketbased reforms see commissioning as a model that promotes greater provider diversity, entrenching the principle of contestability and the competitive approach to the allocation of funding. A parallel policy aspiration is reflected in the fact that commissioning grew in status in a period in which there was governmental interest in expanding the third sector role in the delivery of public services. Thus it was hoped that commissioning would provide a more 'holistic' and 'intelligent' approach than narrow procurement (Osborne and McLaughlin, 2002; Carmel and Harlock, 2008). Indeed, such rhetoric has continued under a Conservative government even as the 'Big Society' discourse has been jettisoned. The overall finding of the research is that the status of commissioning remains contested and its longer-term development, and impact, is far from certain. The question 
of whether commissioning is a genuinely novel approach, bringing about a transformation in 'purchasing' practices, and capable in the longer term of delivering the sorts of outcomes hoped for by policymakers and politicians, remains uncertain at this local level. Caution is therefore required from both advocates and critics of commissioning.

The research took a quasi-longitudinal perspective and, on the question of change, the data reveal a significant experience of underlying continuity across the period in which commissioning has been introduced. Research participants struggled to identify a 'before' or 'after' commissioning, although they were cognisant of the complex layers of policy and practice development that have influenced what is at its core a public sector function concerned with purchasing services. Consequently, it is difficult to isolate the impact that commissioning as a process has had on the relationship between commissioners and providers. The paper identifies two main reasons underlying this continuity. Firstly the fundamental experience of many providers was of an enduring funding relationship with public sector agencies. Many providers had been contracted for a long period, outlasting various policy shifts; and they could also point to longstanding collaborative and communicative relationships with individual commissioners. Secondly, providers often felt that 'little had changed' given that negative experiences - poor communication, failure to consult, 'chaos' and 'u-turns', and numerous specific quibbles over contractual issues - characterised the entire period, regardless of the overarching policy paradigm.

Somewhat contrasting with this strong strand of continuity, respondents (commissioners and TSOs) did point to more limited evidence that commissioning had had a - largely positive - impact on practice. This reflects the fact that reforms have been incremental: they have been used to reshape and redesign particular services, and to bring in a limited range of new providers, rather than to usher in a 'revolution'. Arguably this reflects the skill of commissioners and other stakeholders in maintaining services in sometimes difficult circumstances. Positive interpretations of this shift highlighted that it had introduced a more rigorous approach to planning, monitoring and regulating providers, implying a more effective use of public money, as well as a greater focus on outcomes (including recovery) and service improvement. While perhaps not yet fully realised, for both sides of the commissioning divide, it appears to have created a more deliberative space in which to reassess the value and impact of services and modes of delivery. A more negative interpretation linked the commissioning approach with the adoption of 'managerial' practices, including the more widespread use of online forms of communication and the adoption of inflexible appraisal approaches that were seen as 'tick boxy', 'clinical' and 'dehumanised' - in contrast to the more flexible and personal approaches which were thought to have dominated in the past. This research did not have as one 
of its aims the intention to evaluate claims about the impact of commissioning on the quality of frontline services. Nevertheless, it is possible to observe that commissioners felt somewhat removed from such assessments (or it was not part of their 'performance metrics'). TSO providers, meanwhile, considered such assessments to be very difficult, acknowledging the range of confounding factors impacting on quality (such as cuts to other services and increasing demands).

The findings reported here chime with previous research (Checkland et al., 2012; Harlock, 2014) which suggests that commissioning is difficult, conflicted and often 'incomplete'. It neither represents the fulfilment of aspirations for fully marketised services, nor for the holistic or entirely deliberative process advocated by others. A further key finding therefore is that commissioning should be understood as a highly relational activity. Public sector commissioners have to balance competing priorities that are sometimes hard to reconcile. Commissioners are aware that they represent a public sector purchasing function that must be seen to be robust and above suspicion. They stressed the need for professionalism in dealing with providers and the necessity of running clear and transparent processes. At the same time, policy and guidance requires commissioners to 'manage' a market of providers in order to promote diversity, and this requires a relational mindset that includes fostering and maintaining personal relationships. Thus it can be seen that the principles and practice of 'contestability' is in tension with the requirement to work relationally. Further, there is often a sense in which commissioners and providers are mutually dependent on each other for the continuation of services: at worst the cessation of certain services would bring political risks for the public sector and their partners. Moreover, many TSOs were insistent they knew far more about the services and their users (i.e. information asymmetry) suggesting that commissioners could not easily replace specific providers, at least not without significant upheaval.

Overall, these findings have considerable import for policy discussions of commissioning in the context of further rounds of reform to public services in England. Commissioners are the lynchpin of the commissioning approach and it is clear that the importance of individual commissioners (and some were very highly rated by TSOs for their individual skills and attributes) makes the issue of staff skills and capacity particularly important. It is apparent that commissioning systems are particularly vulnerable to staff 'churn' and organisational capacity constraints, which appear to have been exacerbated in the context of the fiscal austerity implemented since 2010. We advocate caution therefore in portraying commissioning as either the revolutionary approach heralded by advocates, or most feared by critics, and suggest a need for further grounded research into the realities of commissioning especially at the local level. The research suggests that commissioning is in reality more 'political' and open to social construction than 
has often been acknowledged in academic and policy debates. Furthermore, there may be 'hidden agendas' within this arena which are rarely publicly acknowledged (and which by their nature are hard to research).

\section{Acknowledgements}

The support of the Economic and Social Research Council (ESRC), the Office for Civil Society (OCS) and the Barrow Cadbury UK Trust is gratefully acknowledged. This work was part of the programme of the joint ESRC, OCS and Barrow Cadbury Third Sector Research Centre.

The authors would like to thank David Mullins, Ross Millar and Natasha Williams who assisted in various ways in the research, as well as all the participants in the study who so generously gave their time and insights. They would also like to thank the two anonymous referees for their constructive comments.

\section{Ethical statement}

All research conducted at the Third Sector Research Centre was covered by an agreement with the University of Birmingham Research Ethics Committee, which included an agreement to retain all communication on ethical issues (such as interview permissions) and report on a regular basis to the Committee. It was also predicated on the assumption that none of the research would be with children or vulnerable adults. In addition, none of the participants in the research reported here were patients or service users.

\section{References}

Blatchford, K. and Gash, T. (2012), Commissioning for success: how to avoid the pitfalls of open public services, London: Institute for Government.

Bovaird, T., Dickinson, H. and Allen, K. (2012), Commissioning Across government: review of evidence, Research Report 86, Birmingham: Third Sector Research Centre.

Buckingham, H. (2009), Competition and contracts in the voluntary sector: exploring the implications for homelessness service providers in Southampton, Policy and Politics, 37(2): 235-254.

Cabinet Office (2006), Partnership in Public Services: An action plan for third sector involvement. London: Cabinet Office.

Carmel, E. and Harlock, J. (2008), 'Instituting the 'third sector' as a governable terrain: partnership, procurement and performance in the UK', Policy \& Politics, 36(2): 155-171.

Centre for Economic Performance (CEP) (2012), How mental illness loses out in the NHS, http://cep.lse.ac.uk/_new/research/mentalhealth/ (accessed, 1.9.15).

Checkland, K., Harrison, S., Snow, S., McDermott, I. and Coleman, A. (2012), Commissioning in the English National Health Service: What's the Problem? Journal of Social Policy, 41(3): 533-550.

Creswell, J. W. and Clark, V. L. P. (2011), Designing and conducting mixed methods research, London: Sage.

Davies, S. (2008), Contracting out employment services to the third and private sectors: A critique, Critical Social Policy, 28(2): 136-164.

Department of Health (DoH) (2011), No health without mental health, London: HM Government.

Department of Health (DoH) (2012), No health without mental health: implementation framework, London: HM Government. 
Dickinson, H., Jeffares, S., Nicholds, A. and Glasby, J. (2014), Beyond the Berlin Wall? Investigating joint commissioning and its various meanings using a $\mathrm{Q}$ methodology approach, Public Management Review, 16(6): 830-851.

Dominey, J. (2012), A mixed market for probation services: Can lessons from the recent past help shape the near future? Probation Journal, 59(4): 339-354.

Gale, N. K., Heath, G., Cameron, E., Rashid, S. and Redwood, S. (2013), Using the framework method for the analysis of qualitative data in multi-disciplinary health research, BMC medical research methodology, 13(1): 117.

Glasby, J. (ed.) (2012), Commissioning for health and well-being: An introduction, Bristol: Policy Press.

Harlock, J. (2014), 'Diversity and Ambiguity in the English Third Sector: Responding to Contracts and Competition in Public Service Delivery,' in Brandsen, T., Trommel, W. and Verschuere, B. (eds) Manufacturing Civil Society: Principles, Practices and Effects, Basingstoke: Palgrave.

Heginbotham, C. and Newbigging, K. (2013), Commissioning Health and Wellbeing. London: Sage.

HM Government (2011), Open Public Services White Paper, London: TSO.

House of Commons Health Committee (2010), Commissioning: Fourth Report of Session 2009-10, London: Stationery Office.

Huxley, P., Maegusuku-Hewett, T., Evans, S., Cornes, M., Manthorpe, J. and Stevens, M. (2010), Better evidence for better commissioning: a study of the evidence base of generic social care commissioning guides in the UK, Evidence \& Policy 6(3): 291-307.

Institute of Public Care (IPC) (2008), The Role of Commissioning in Improving Services to Children in Need, https://ipc.brookes.ac.uk/publications/The_Role_of_Commissioning in_Improving_Services_to_Children_in_Need.pdf, downloaded 20.06.16.

King's Fund and Centre for Mental Health (2012), Long-term conditions and mental health: The cost of co-morbidities, http://www.kingsfund.org.uk/publications/long-termconditions-and-mental-health (accessed 1.9.15).

Larner, W. and Butler, M. (2005), Governmentalities of local partnerships: the rise of a "partnering state" in New Zealand, Studies in Political Economy, 75: 85-108.

Lonsdale, C. (2012), 'Procurement and Market Management', in Glasby, J. (ed.) (2012), Commissioning for health and well-being: An introduction, Bristol, Policy Press.

Macmillan, R. (2010), The third sector delivering public services: an evidence review, Birmingham: TSRC.

Macmillan, R., Taylor, R., Arvidson, M., Soteri-Proctor, A. and Teasdale, S. (2013), The third sector in unsettled times: a field guide, Birmingham: TSRC.

Martikke, S. and Moxham, C. (2010), Public Sector Commissioning: Experiences of Voluntary Organizations Delivering Health and Social Services, International Journal of Public Administration, 33: 790-799.

Mental Health Strategies (2012), 2011/12 National survey of investment in adult mental health services, www.gov.uk/government/uploads/system/uploads/attachment_data/file/140098/ FinMap2012-NatReportAdult-0308212.pdf (accessed 1.9.15).

Milbourne, L. and Cushman, M. (2015), Complying, transforming or resisting in the new austerity? Realigning social welfare and independent action among English voluntary organisations. Journal of Social Policy, 44(3): 463-485.

Miller, R. (2013), Third sector organisations: unique or simply other qualified providers? Journal of Public Mental Health, 12(2): 103-112.

Miller, R. and Rees, J. (2014), Mental health commissioning: master or subject of change?, Mental Health Review Journal, 19(3): 145-155.

Murray, J. (2011), Third Sector Commissioning and English Local Government Procurement, Public Money \& Management, 31(4): 279-286.

Navca (2010), A Bridge Between Two Worlds: A Study of Support and Development Organisations and Intelligent Commissioning, Sheffield: Navca. 
Nevile, A. (2010), Drifting or holding firm? Public funding and the values of third sector organisations Policy and Politics 38(4): 531-46.

ODPM/LGA (2003), National Procurement Strategy for Local Government, London: HMSO.

Osborne, S. and McLaughlin, K. (2002), Trends and issues in the implementation of local 'voluntary sector compacts' in England, Public Money \& Management, 22(1): 55-63.

Packwood, D. (2007), Commissioning, Contracting and Service Delivery of Children's Services in the Voluntary and Community Sector, London: VCS Engage.

Rees, J. (2014), Public sector commissioning and the third sector: old wine in new bottles? Public Policy and Administration, 29(1): 45-63.

Slade, M. (2009), Personal recovery and mental illness: A guide for mental health professionals. Cambridge: Cambridge University Press.

University of Birmingham (2014), Commissioning for Better Outcomes: A Route Map, Birmingham: HSMC.

White, L. (2011), Commission Impossible? Shaping places through strategic commissioning, Localis/Essex County Council. 